\title{
Descripción radiológica de la osteología del mono tití de Goeldi (Callimico goeldii) mantenido en cautiverio
}

\author{
RADIOLOGICAL DESCRIPTION OF THE OSTEOLOGY OF GOELDI's MARMOSET (Callimico \\ goeldii) KEPT IN CAPTIVITY
}

\author{
Ricardo Grandez R. ${ }^{1,2}$, Paola Rodríguez D. ${ }^{1}$, Catalina Hermoza G. ${ }^{1}$
}

\section{Resumen}

\begin{abstract}
El estudio tuvo como objetivo describir radiológicamente la osteología del mono tití de Goeldi (Callimico goeldii). Se emplearon cinco individuos en estado de cautiverio, en aparente buen estado de salud, del Parque Zoológico Huachipa (Lima, Perú). Se les realizó un examen clínico previo para constatar el buen estado de salud. Los animales fueron anestesiados y posicionados en decúbito dorsal y lateral para la evaluación radiológica. Asimismo, se obtuvo vistas del esqueleto apendicular y se hizo un registro de distintos valores de exposición para determinar los valores óptimos de estos. Los resultados mostraron que los valores de exposición óptimos para obtener imágenes radiográficas en esta especie para cabeza y tórax-abdomen fueron en posición dorso ventral y lateral $50 \mathrm{Kv}, 20 \mathrm{~mA}, 0.03 \mathrm{~s}$ y para las extremidades en vista medio lateral de $50 \mathrm{kV}$, $20 \mathrm{~mA}, 0.02 \mathrm{~s}$. Se evidenció que la tibia y el peroné se encuentran fusionados en su tercio inferior y poseen una curvatura hacia distal, ancho máximo de la pelvis es a nivel de las eminencias iliopúbicas, y las proporciones de las cuatro extremidades de esta especie son menores a las proporciones de otros primates neotropicales. Del presente estudio se puede concluir que existen diferencias morfológicas a nivel de la pelvis y las extremidades posteriores con relación a otras especies de primates, posiblemente debidas al patrón de locomoción por saltos verticales en Callimico goeldii.
\end{abstract}

Palabras clave: osteología; radiología; morfología; Callimico goeldii

\footnotetext{
${ }^{1}$ Clínica Veterinaria Docente Cayetano Heredia, Departamento Académico de Medicina Veterinaria y Zootecnia, Facultad de Medicina Veterinaria y Zootecnia, Universidad Peruana Cayetano Heredia, Lima, Perú

${ }^{2}$ E-mail: rgrandez@hotmail.com
}

Recibido: 23 de septiembre de 2017

Aceptado para publicación: 17 de enero de 2018 
The objective of the study was to radiologically describe the osteology of the Goeldi's marmoset (Callimico goeldii). Five individuals reared in captivity, in apparently good health, of the Huachipa Zoological Park (Lima, Peru) were used. They underwent a previous clinical examination to verify the good state of health. The animals were anesthetized and positioned in dorsal and lateral decubitus for radiological evaluation. Likewise, views of the appendicular skeleton were obtained and a record of different exposure values was made to determine their optimum values. The results showed that the optimal exposure values to obtain radiographic images in this species for head and thorax-abdomen were dorso-ventral and lateral views of $50 \mathrm{Kv}, 20 \mathrm{~mA}, 0.03 \mathrm{~s}$ and for the extremities mediallateral view of $50 \mathrm{kV}, 20 \mathrm{~mA}, 0.02 \mathrm{~s}$. It was evidenced that the tibia and the fibula are fused in their lower third and have a distal curvature, the pelvis has its maximum width at the level of the iliopubic eminences, and the proportions of the four limbs of this species are less than proportions of other Neotropical primates. From the present study it can be concluded that there are morphological differences at the level of the pelvis and hind limbs in relation to other primate species, possibly due to the locomotion pattern by vertical jumps in this species.

Key words: osteology; radiology; morphology; Callimico goeldii

\section{INTRODUCCIÓN}

El tití de Goeldi (Callimico goeldii) es un mamífero de la orden Primate, familia Callitrichidae, subfamilia Callitrichinae, la cual está conformada por tamarinos y titíes, y conocidos como primates neotropicales (Napier y Napier, 1985; Groves, 2001). Ha sido descrita como la única especie del género Callimico (Rylands et al., 1995); sin embargo, hay indicios que puede existir más de una especie en el género (Cornejo, 2008), no siendo concluyentes hasta el momento los estudios de filogenética molecular realizados (Schneider y Sampaio, 2015). Esta especie es natural de América del Sur y su distribución comprende Colombia, Ecuador, Perú, Brasil y Bolivia. Es de hábitos diurnos y arborícolas, su alimentación varía según la temporada del año, su pelaje es de color pardo oscuro con la cola negra, las medidas de la cabeza al cuerpo son entre 18 y $23 \mathrm{~cm}$ y la cola entre de 25 y $32 \mathrm{~cm}$. Su peso varía entre 400 y 535 g (machos: $499 \mathrm{~g}$; hembras: $468 \mathrm{~g}$ ). Posee pobre dimorfismo sexual y puede re- producirse dos veces por año, usualmente con una cría por parto (Napier y Napier, 1985; Turnquist y Hong, 1995).

La imagenología es un medio no invasivo de diagnóstico para ver estructuras biológicas, permitiendo identificar alteraciones patológicas (Kiessling y Pichler, 2011), constituyendo muchas veces, en conjunto con la clínica, el primer paso del diagnóstico para lograr el diagnóstico definitivo o descartar otras causas (Fernández y Moreno, 2004). El principal uso de la radiografía son los problemas óseos; no obstante, las radiografías también son útiles para diagnosticar neumonías, neoplasias, edemas pulmonares y otras patologías de tejidos blandos (Lannoo, 2008).

El esqueleto del tití de Goeldi consta del mismo número de huesos que en los humanos, con la excepción de vértebras caudales adicionales (Fleagle, 1999). El cráneo es globular, que forma una frente sobre las órbitas oculares demarcada por los surcos supraorbitales y separados en la línea media por un área relativamente deprimida; y el 
occipucio es más convexo que la frente (Preuschoft, 2000). Los huesos nasales son cortos y aplanados, y las cavidades de las órbitas oculares están redondeadas y dirigidas frontalmente (Hill, 1957). La mandíbula es corta y robusta, la región angular de la mandíbula es excepcionalmente grande, puesto que produce movimientos hacia abajo y hacia atrás (Richter et al., 1984).

La columna vertebral difiere poco a la humana, y debido a su postura cuadrúpeda y la situación de las extremidades, desarrolla un arco dorsal posterior; sin embargo, en la parte cervical se presenta una tendencia a la convexidad ventral, relacionado con la necesidad de colocar el cráneo con presentación frontal en la postura cuadrúpeda, pero fácilmente modificable cuando se coloca el tronco en posición vertical (Hill, 1957). El tórax es más corto y abarrilado que otras especies de esta superfamilia; con la clavícula bien desarrollada y relativamente larga. La escápula tiene un largo borde axial y ventral (Varela, 2005). El radio y el cúbito están separados y son relativamente cortos en esta familia, el olécranon suele ser largo y el proceso estiloides articula directamente con los huesos central y cuneiforme del carpo (Fleagle, 1999). Los huesos de la mano están desarrollados; los metacarpianos son largos y están arqueados ventralmente; y las falanges son atípicas, lo cual se relaciona con la presencia de garras, que están comprimidas lateralmente y son puntiagudas en su parte distal (Fleagle, 1999).

Las regiones sacra y lumbar están en alineación, pero cuando se asume la postura ortógrada incrementa la tendencia a la formación de una curva sigmoidea en la unión lumbosacra. Esta especie tiene una cola larga con 27 vértebras caudales. Los arcos neurales están completos en las primeras seis vértebras caudales y las demás solo poseen los procesos articular y transverso (Hill, 1957). El isquion está caracterizado por el desarrollo de tuberosidades sin callosidad, y la longitud isquiática es mayor en macho que en hembras (Hershkovitz, 1977). El fémur es relativamente más corto en esta subfamila, con solo $37 \%$ del largo del tronco, y es recto y no curvado como en otras especies; en tanto que la tibia y el peroné están separados, donde cada hueso se une proximal y distalmente mediante una articulación sinovial. La tibia es más larga, pero no más ancha que el fémur y está curvada en el primer tercio (Hill, 1957).

La totalidad del esqueleto podal es alargado y estrecho transversalmente, con los elementos radiales (metatarsos y falanges) comprimidos, exceptuando el primer dedo del miembro pélvico, que se presenta divergente y parcialmente oponible; las falanges distales del pie son similares a las de la mano, pero el primer dedo del miembro pélvico está aplanado dorso ventralmente (Hill, 1957).

El presente estudio tuvo como finalidad describir radiológicamente la osteología del mono tití de Goeldi (Callimico goeldii), con el fin de determinar los parámetros normales de la especie, lo cual permitiría implementar un mejor manejo clínico y facilitando el diagnóstico imagenológico de ciertas patologías.

\section{Materiales y Métodos}

El estudio radiológico se realizó en el Parque Zoológico Huachipa (PZH), ubicado en el distrito de Ate Vitarte, Lima, Perú. El estudio fue de tipo descriptivo y permitió determinar radiológicamente las características de la osteología de ejemplares de Callimico goeldii mantenidos en cautiverio en el PZH. El tamaño de muestra correspondió al total de ejemplares mantenidos en cautiverio en el PZH que se encontraban con aparente buen estado de salud, sin tratamiento y libres de enfermedades previas en los últimos tres meses, y que no se encontraban en gestación. Para comprobar el estado de los animales se realizó el examen clínico completo, a cargo del médico veterinario del Área de Veterinaria del PZH. 


\section{Pesajes y Dosificación}

La contención y anestesia de los animales la realizó el personal médico veterinario, según el protocolo de anestesia establecido para esta especie en el PZH, el cual consta de la captura del individuo con una malla, para luego ser pesado y dosificado vía i.m. con xilazina $(0.5 \mathrm{mg} / \mathrm{kg})$, ketamina $(10$ $\mathrm{mg} / \mathrm{kg})$ y con midazolam $(0.2 \mathrm{mg} / \mathrm{kg})$ a una sola dosis.

\section{Tomas Radiográficas}

Para las tomas radiográficas se utilizó el equipo de Rayos X MinXray HF 100 perteneciente al $\mathrm{PZH}$ y placas radiográficas Kodak Medical X-Ray Film General Purpose Green de 27.9 x $35.6 \mathrm{~cm}$. Los animales fueron posicionados en decúbito dorsal y lateral derecha para la evaluación del esqueleto axial $\mathrm{y}$ vistas medio lateral para el esqueleto apendicular. Se hizo un registro de distintos valores de exposición para la obtención de vistas de calidad radiográfica y así determinar los valores óptimos de exposición, ya que no se contaba con un protocolo establecido para el manejo radiológico de esta especie. Se utilizó las medidas de radioprotección convencional para estos procedimientos (mandil, guantes y collarín de plomo).

Las placas se revelaron en cuarto oscuro. Las placas se extrajeron del chasis y se colocaron en los colgadores para sumergirlas en el líquido de revelado Kodak GBX Developer and Replenisher por 30 s. Luego fueron enjuagadas en agua para detener el revelado, para luego sumergirlas en el reactivo Kodak GBX Fixer and Replenisher por $2 \mathrm{~min}$ para su fijación. Las placas fueron secadas al ambiente.

\section{Análisis Radiográfico}

Todas las placas fueron revisadas con el uso del negatoscopio convencional. Se tomaron registros fotográficos de todas las placas radiográficas para proceder a la medición del esqueleto. Se realizaron mediciones de la longitud corporal, ancho y largo del cráneo, así como las dimensiones de los huesos húmero, radio, cúbito, fémur, tibia-peroné y pelvis. Además, se determinó el número de vértebras de la columna vertebral y sus dimensiones, y el número de dedos y falanges por extremidad.

\section{Mediciones}

Las mediciones para cada hueso analizado se realizaron tomando en cuenta puntos de referencia específicos para cada uno, adaptado de Ankel-Simons (2007). Se realizaron las medidas de las extremidades para obtener las proporciones con respecto a la medida del cuerpo. Para las mediciones se empleó una regla milimetrada; siendo el milímetro la principal unidad de medida.

\section{Cráneo}

Se tomó en cuenta desde el incisivo superior hasta la cresta externa del occipital, y para la medida del ancho se consideró desde el punto máximo externo del arco cigomático izquierdo hasta el punto máximo externo del arco cigomático derecho. Las medidas se realizaron usando la vista lateral derecha y rostro craneal, respectivamente.

\section{Húmero, radio y cúbito}

Se hizo uso de la vista medio lateral de las extremidades anteriores para estas mediciones.

- Para medir el largo del húmero se tomó como punto de referencia el borde externo del tubérculo mayor del húmero y el borde distal del cóndilo medial, en tanto que para las medidas del ancho del húmero se tomó como referencia el punto medio de la diáfisis del húmero.

- Para las medidas del largo del radio se consideró la cabeza del radio y el borde del proceso estiloides como punto de referencia y para el ancho se consideró el punto medio de la diáfisis del radio. 
- Para medir el largo del cúbito se consideró la tuberosidad del olecranon como punto inicial hasta el borde del proceso estiloides, y para medir el ancho se consideró el punto medio de la diáfisis del cuerpo del cúbito como punto de referencia.

Vértebras cervicales, torácicas, lumbares, sacras y caudales

Tomando en cuenta la vista lateral derecha de las radiografias, se tomaron en consideración las vértebras: $\mathrm{V}$ cervical, $\mathrm{X}$ torácica, IV lumbar, II y III sacra, y XV caudal. Para las mediciones de largo y ancho de las vértebras se consideraron desde los respectivos bordes del cuerpo de cada vértebra.

\section{Pelvis, fémur, tibia-peroné}

Para la realización de estas medidas se consideró la vista radiológica medio lateral.

- La referencia para las mediciones del ancho de la pelvis fue la línea transversal entre las eminencias iliopúbicas, ancho iliopúbico, ya que ese punto era el más ancho desde la vista ventro dorsal de la placa. Para la medida del largo de la pelvis fue considerada desde la cresta iliaca hasta la tuberosidad isquiática, haciendo uso de la vista lateral derecha.

- Para el largo del fémur se tuvo como punto de referencia la cabeza del fémur y el borde distal del cóndilo medial, en tanto que para las medidas del ancho del hueso se tomó como referencia el punto medio de la diáfisis del fémur.

- Para la tibia y peroné, que se encuentran ligeramente fusionados, las mediciones del largo tuvieron como punto de referencia el cóndilo lateral de la tibia y el maléolo externo del peroné, y para la medida del ancho se tomó el punto medio de la diáfisis.
Longitud de manos y pies

- Para medir la longitud de las manos se tomaron en cuenta dos puntos referenciales: la falange distal del III dedo hasta el borde más externo del arco que forman los bordes de los huesos escaloides y semilunar del carpo.

- Para medir la longitud de los pies se tomó en cuenta la falange distal del IV dedo hasta el borde más externo del hueso calcáneo del tarso.

Longitud del tronco corporal, de los brazos, de las piernas, y largo corporal total

- Para realizar la medición de la longitud del tronco corporal se tomaron en consideración dos puntos referenciales: el borde anterior de la primera vértebra cervical y el borde posterior de la tercera vértebra sacra.

- Para medir la longitud de los brazos se tomó en cuenta el borde externo del tubérculo mayor de húmero y el borde externo del proceso estiloides del cúbito.

- Para medir la longitud de las piernas se tomó en cuenta el borde externo de la cabeza del fémur y el borde del maléolo externo del peroné.

- Para realizar la medición del largo corporal total se tomó en consideración la cara dorsal del cráneo y la última vértebra caudal, dando así el largo total incluido la cola. Para está medición se hizo uso de la vista ventro dorsal y lateral derecha.

\section{Estadística}

Los resultados se expresaron en promedios como medida de tendencia central y desvío estándar como medida de dispersión. 
Cuadro 1. Medidas radiológicas de largo y ancho del cráneo, húmero, radio y cúbito de cinco individuos Callimico goeldii mantenidos en cautiverio en el Parque Zoológico Huachipa

\begin{tabular}{lcccccccc}
\hline \multirow{2}{*}{ Espécimen } & \multicolumn{2}{c}{ Cráneo $(\mathrm{mm})$} & \multicolumn{2}{c}{ Húmero $(\mathrm{mm})$} & \multicolumn{2}{c}{ Radio $(\mathrm{mm})$} & \multicolumn{2}{c}{ Cúbito $(\mathrm{mm})$} \\
\cline { 2 - 9 } & Long. & Ancho & Long. & Ancho & Long. & Ancho & Long. & Ancho \\
\hline Macho & - & - & 41.9 & 1.1 & 45.8 & 1.7 & 35.4 & 0.7 \\
Macho & 53.4 & - & 43.1 & 0.7 & 46.4 & 1.8 & 38.8 & 0.8 \\
Macho & - & - & 49.7 & 1.1 & 57.1 & 1.8 & 45 & 0.9 \\
Hembra & 53.6 & 35.8 & 46.5 & 1.2 & 55.1 & 1.7 & 48.9 & 0.8 \\
Hembra & - & 30.1 & 48.2 & 1.1 & 52.1 & 1.6 & 41.4 & 0.5 \\
\hline Media & 53.5 & 32.9 & 45.9 & 1.0 & 51.3 & 1.7 & 41.9 & 0.7 \\
D.E. & 0.1 & 4.0 & 3.3 & 0.2 & 5.1 & 0.1 & 5.3 & 0.1 \\
\hline
\end{tabular}

Cuadro 2. Medidas radiológicas de largo y ancho de la tibia-peroné, pelvis y fémur de cinco individuos Callimico goeldii mantenidos en cautiverio en el Parque Zoológico Huachipa

\begin{tabular}{lcccccccc}
\hline & \multicolumn{3}{c}{$\begin{array}{c}\text { Tibia-Peroné } \\
(\mathrm{mm})\end{array}$} & \multicolumn{4}{c}{ Pelvis $(\mathrm{mm})$} \\
\cline { 2 - 9 } Espécimen & Long. & Ancho & Long. & $\begin{array}{c}\text { Ancho } \\
\text { craneal }\end{array}$ & $\begin{array}{c}\text { Ancho } \\
\text { caudal }\end{array}$ & $\begin{array}{c}\text { Ancho } \\
\text { iliopúbico }\end{array}$ & Long. & Ancho \\
\cline { 2 - 9 } & - & - & 44.3 & 20 & 18.5 & 21.4 & 62.2 & 2.2 \\
Macho & 68.6 & 1.4 & 46.7 & 25.3 & 18.4 & 28.4 & 67.8 & 2.1 \\
Macho & - & - & 51.8 & 23.3 & 18.4 & 25.4 & 69.1 & 1.9 \\
Macho & 72.2 & 1.2 & 52.9 & 21.4 & 20.7 & 22.3 & 74.1 & 2.1 \\
Hembra & - & - & 48.6 & 23.1 & 17.4 & 24.6 & 69.5 & 1.5 \\
Hembra & 70.4 & 1.3 & 48.9 & 22.6 & 18.7 & 24.2 & 68.5 & 1.9 \\
\hline Media & 2.6 & 0.1 & 3.6 & 2.0 & 1.2 & 2.8 & 4.2 & 0.2 \\
D.E. & & & & & & & & \\
\hline
\end{tabular}

Cuadro 3. Medidas de largo y ancho de las vértebras de cinco individuos de Callimico goeldii mantenidos en cautiverio en el Parque Zoológico Huachipa

\begin{tabular}{lcccccccccc}
\hline Espécimen & \multicolumn{2}{c}{$\begin{array}{c}\text { Cervicales } \\
(\mathrm{mm})\end{array}$} & \multicolumn{2}{c}{$\begin{array}{c}\text { Torácicas } \\
(\mathrm{mm})\end{array}$} & \multicolumn{2}{c}{$\begin{array}{c}\text { Lumbares } \\
(\mathrm{mm})\end{array}$} & \multicolumn{2}{c}{$\begin{array}{c}\text { Sacras } \\
(\mathrm{mm})\end{array}$} & \multicolumn{2}{c}{$\begin{array}{c}\text { Caudales } \\
(\mathrm{mm})\end{array}$} \\
\cline { 2 - 11 } & Long. & Ancho & Long. & Ancho & Long. & Ancho & Long. & Ancho & Long. & Ancho \\
\hline Macho & 0.9 & 2.4 & 2.8 & 2.6 & 7.8 & 4.8 & 14.3 & 1.7 & 14.6 & 0.3 \\
Macho & - & - & - & - & - & - & - & - & - & - \\
Macho & 1.7 & 2.2 & 2.1 & 2.0 & 8.1 & 3.0 & - & - & 15.6 & 0.8 \\
Hembra & - & - & - & - & - & - & - & - & - & - \\
Hembra & 1.6 & 3.1 & 3.1 & 3.4 & 9.2 & 4.6 & - & - & - & - \\
\hline Media & 1.4 & 2.6 & 2.7 & 2.7 & 8.4 & 4.1 & 14.3 & 1.7 & 15.1 & 0.6 \\
D.S. & 0.4 & 0.5 & 0.5 & 0.7 & 0.7 & 1.0 & 0.0 & 0.0 & 0.7 & 0.4 \\
\hline
\end{tabular}


Cuadro 4. Longitud corporal total, del tronco y de las extremidades anteriores y posteriores de cinco individuos de Callimico goeldii mantenidos en cautiverio en el Parque Zoológico Huachipa

\begin{tabular}{lcccccc}
\hline Espécimen & $\begin{array}{c}\text { Manos } \\
(\mathrm{mm})\end{array}$ & $\begin{array}{c}\text { Pies } \\
(\mathrm{mm})\end{array}$ & $\begin{array}{c}\text { Brazos } \\
(\mathrm{mm})\end{array}$ & $\begin{array}{c}\text { Piernas } \\
(\mathrm{mm})\end{array}$ & $\begin{array}{c}\text { Tronco } \\
(\mathrm{mm})\end{array}$ & $\begin{array}{c}\text { L. corporal } \\
(\mathrm{mm})\end{array}$ \\
\hline Macho & - & 45.6 & 123.1 & 132.6 & 164.4 & 491.3 \\
Macho & - & - & 128.3 & 136.4 & 160.2 & 487.1 \\
Macho & 34.5 & 46.3 & 151.8 & 139.5 & 172.2 & 499.1 \\
Hembra & 46.4 & 55.4 & 150.5 & 146.3 & 167.7 & 497.5 \\
Hembra & 38.7 & - & 141.7 & 139.9 & 177.4 & 501.5 \\
\hline Media & 39.9 & 49.1 & 139.1 & 138.9 & 168.4 & 495.3 \\
D.S. & 6.0 & 5.5 & 12.9 & 5.1 & 6.7 & 5.9 \\
\hline
\end{tabular}

\section{Resultados}

Se evaluaron cinco ejemplares Callimico goeldii que cumplieron los criterios de inclusión. Adultos, tres machos y dos hembras, con peso promedio de $457 \mathrm{~g}$. El examen clínico evidenció resultados dentro de los rangos normales para la especie, con promedios de: frecuencia cardiaca de 304 lat/ minuto, frecuencia respiratoria de $67 \mathrm{resp} /$ minuto, y temperatura corporal de $38.4{ }^{\circ} \mathrm{C}$. Los valores de exposición óptimos para obtener las imágenes radiográficas fueron para la cabeza y tórax-abdomen en posición ventro dorsal y lateral derecha de $50 \mathrm{kV}, 20 \mathrm{~mA}$, $0.03 \mathrm{~s}$ y para las extremidades en las vistas medio laterales de $50 \mathrm{kV}, 20 \mathrm{~mA}, 0.02 \mathrm{~s}$.

Los resultados de las medidas de largo y ancho del cráneo, húmero, radio y cúbito se muestran en el Cuadro 1. Si bien se pudo identificar los componentes de la cintura escapular, no pudieron ser medidas por la sobre posición de los huesos del tórax. La escápula presentaba forma triangular y plana y la clavícula se observó como un hueso largo en forma de una $\mathrm{S}$ alargada.
Las medidas de largo y ancho de la pelvis, fémur y tibia-peroné se muestran en el Cuadro 2, Se tomó en cuenta solo una medida para la tibia y el peroné, ya que se encuentran aparentemente fusionados en su tercio inferior, observándose como hueso único, por la curvatura que poseen hacia distal. Por otro lado, la pelvis tiene una forma distinta a la mencionada en la literatura, ya que su ancho máximo es a nivel de las eminencias iliopúbicas, razón por la cual se hicieron tres medidas del ancho, ancho craneal, caudal y a nivel de las eminencias iliopúbicas.

Los huesos del carpo consistían en 10 huesos y el metacarpo tenía cinco piezas nombradas del I al V de medial a lateral. Los huesos del tarso consistían en seis huesos y el metatarso tenía cinco piezas nombradas del I al V de medial a lateral. En cada extremidad había cinco falanges, cada una compuesta por falange proximal, medial y distal; excepto el primer dedo de la mano y el pie que poseen solo falange proximal y distal.

Las medidas de largo y ancho de las vértebras del esqueleto axial se muestran en el Cuadro 3. Se dispone de 7 cervicales, 12 

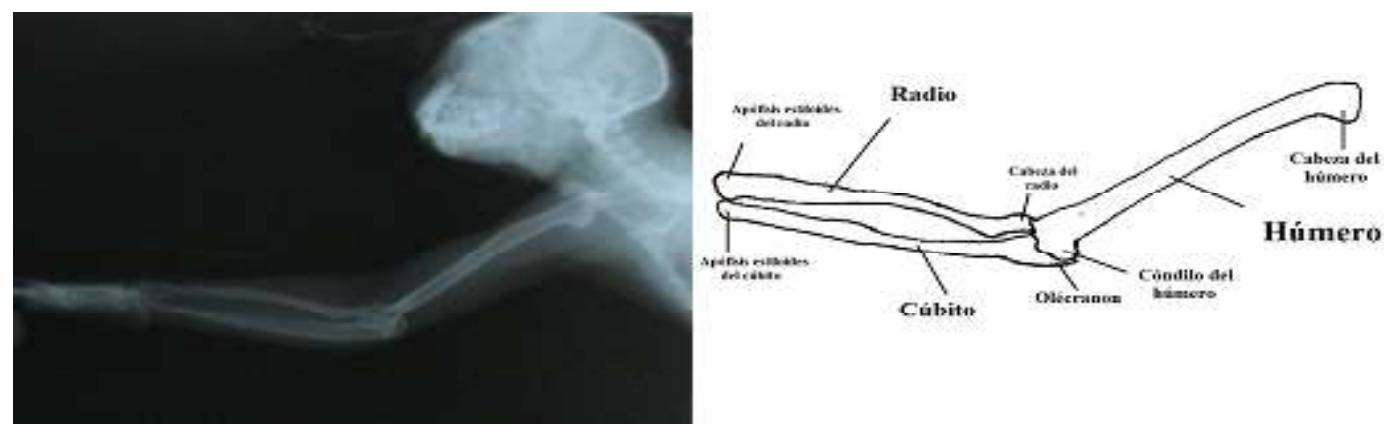

Figura 1. Imagen radiográfica media lateral y esquema del miembro anterior de los huesos húmero, radio y cúbito de Callimico goeldii mantenido en cautiverio en el Parque Zoológico Huachipa
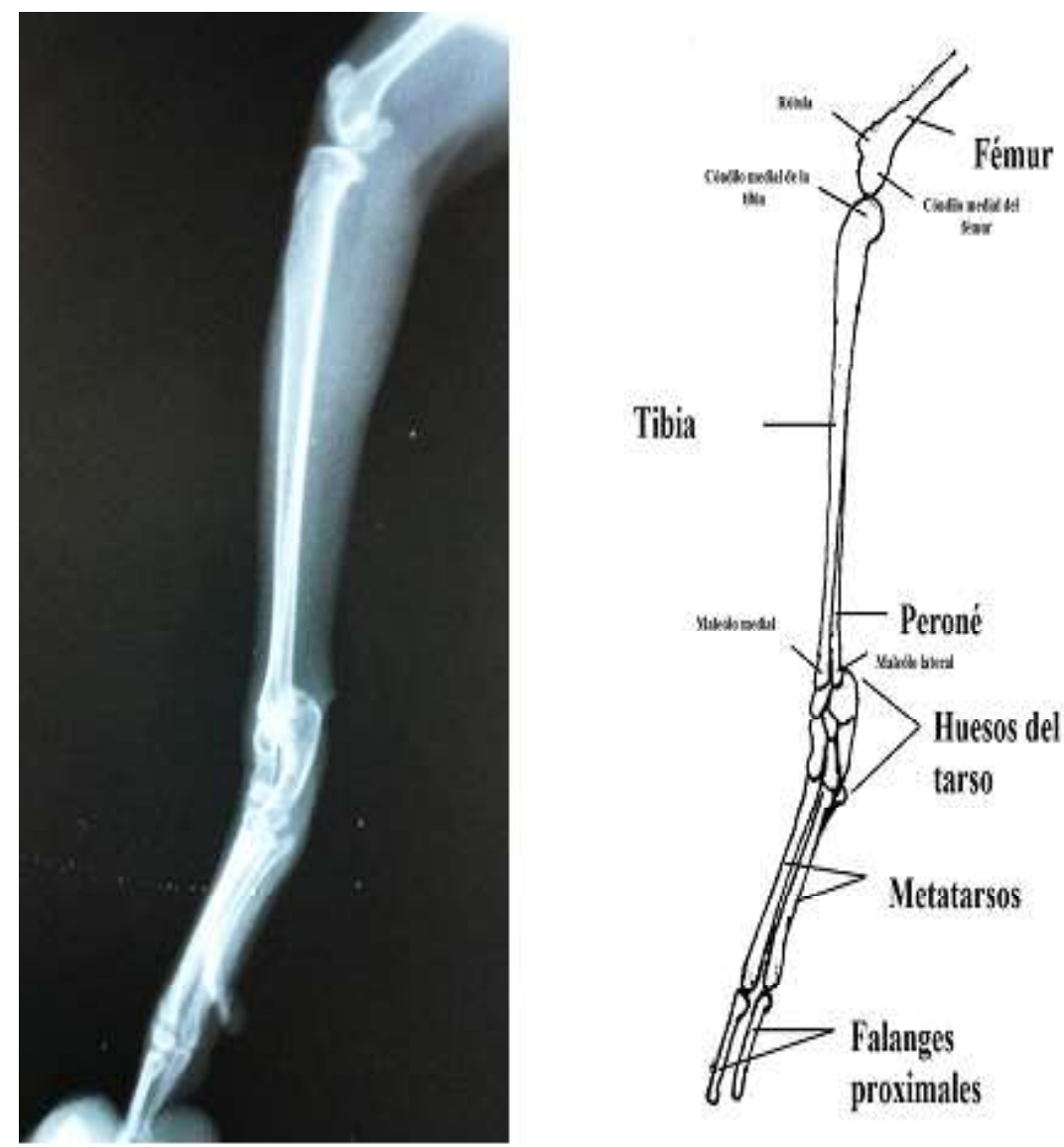

Figura 2. Imagen radiográfica medio lateral y esquema de los huesos del miembro posterior de Callimico goeldii mantenido en cautiverio en el Parque Zoológico Huachipa 

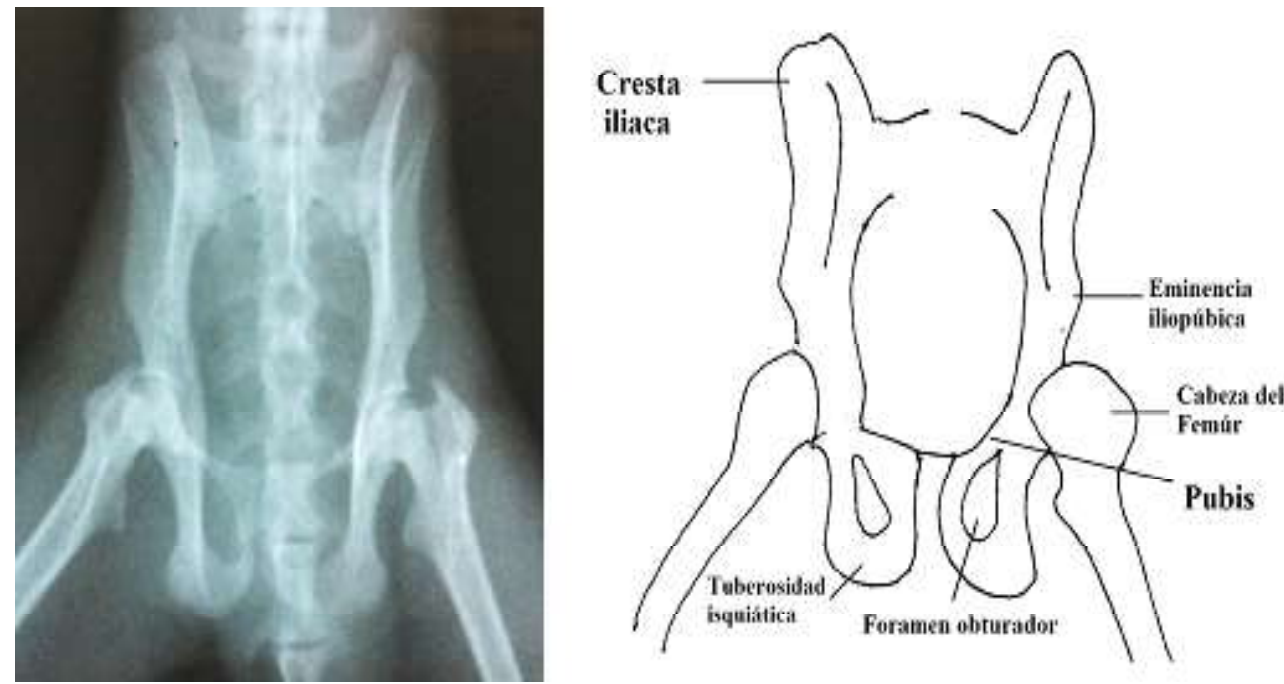

Figura 3. Imagen radiográfica ventro dorsal y esquema de la pelvis ósea de Callimico goeldii mantenido en cautiverio en el Parque Zoológico Huachipa
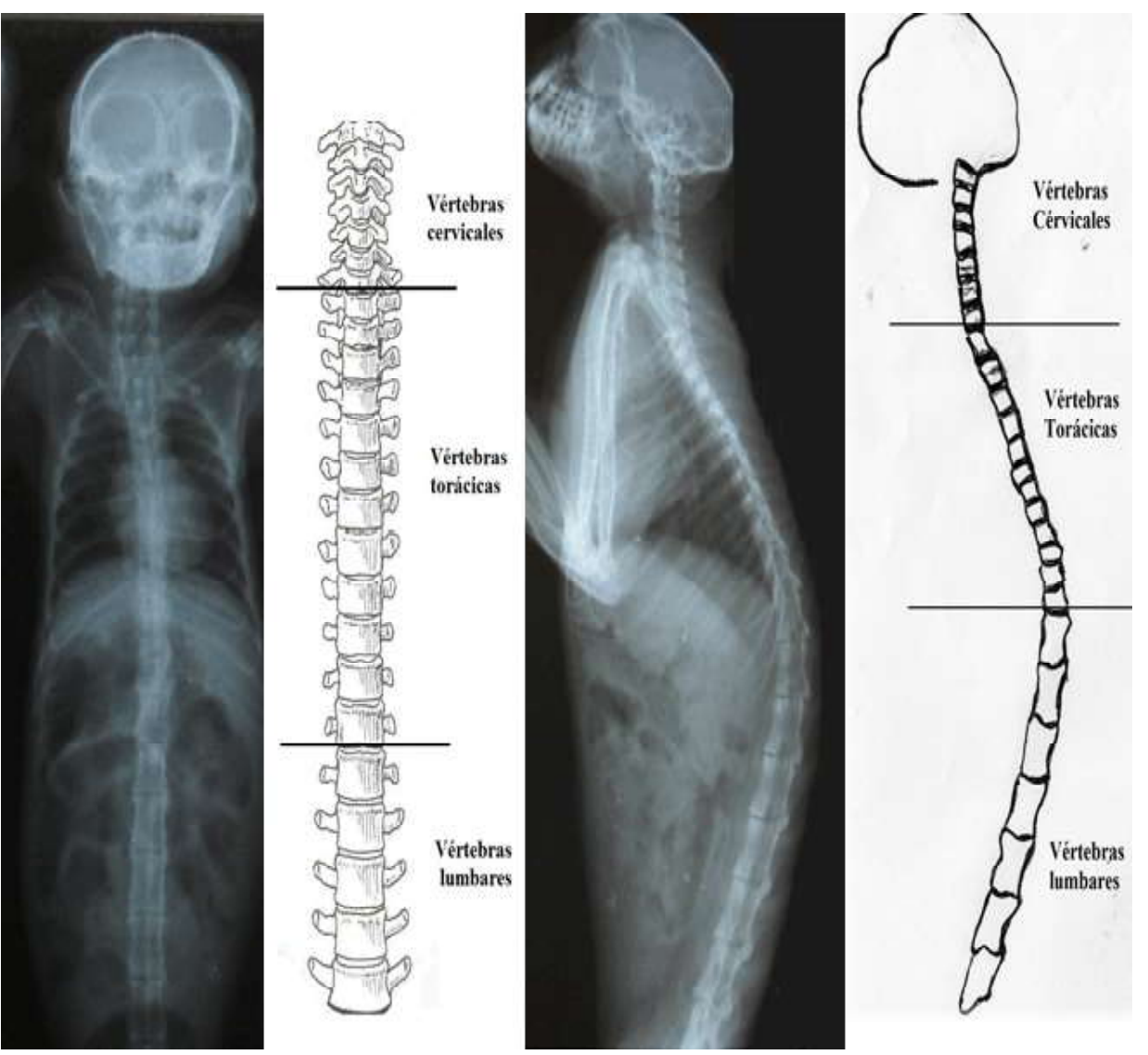

Figura 4. Imágenes radiográficas ventro dorsal y lateral derecha, y esquema de la columna vertebral de Callimico goeldii mantenido en cautiverio en el Parque Zoológico Huachipa. Adaptado de Ankel-Simons (2007) 
torácicas, 7 lumbares, 3 sacras y 27 coccígeas. El número de costillas correspondió al número de vértebras torácicas unidas al esternón. Así mismo, la longitud corporal total, longitud del tronco, longitud de brazos, piernas, manos y pies se muestran en el Cuadro 4; siendo las proporciones de la longitud corporal con la longitud de la mano de $23.3 \%$, del pie de $29.2 \%$, del brazo $82.5 \%$ y de la pierna $82.6 \%$.

No se observaron diferencias resaltantes en las medidas de las estructuras óseas y proporciones entre hembras y machos, siendo de $24.8 \%$ en mano, $33 \%$ en pie, $84.8 \%$ en brazo y $83.1 \%$ en pierna para las hembras y de $20 \%$ en mano, $27.3 \%$ en pie, $81 \%$ en brazo y $82.3 \%$ en pierna para los machos. En forma similar, la longitud del esqueleto de la hembra fue de $499.5 \mathrm{~mm}$ y en machos de $492.5 \mathrm{~mm}$.

A partir de las imágenes radiográficas se elaboraron esquemas de la anatomía radiológica de $C$. goeldii, donde se aprecian los componentes del esqueleto óseo de la especie (figuras 1 a 4)

\section{Discusión}

Los valores de exposición óptimos para obtener las imágenes radiográficas en esta especie fueron establecidos a partir de pruebas previas, considerando como base los valores de exposición radiográfica de la mano humana de talla y edad media, lográndose imágenes de calidad y de valor diagnóstico.

La forma y medidas del cráneo, húmero, radio y cúbito de Callimico goeldii guardan relación con las especies de la misma subfamilia (Ankel-Simons, 2007). El largo del fémur correspondió al 34\% de la medida del tronco del animal; describiéndose que el fémur, en la familia Callitrichidae, corresponde al $37 \%$ de la medida del tronco (AnkelSimons, 2007), lo que muestra que esta especie comparte proporciones de su esqueleto con las demás especies de otros géneros de la familia; asimismo, se observó que los promedios observados de las proporciones de las extremidades y largo corporal total no fueron diferentes entre sexos.

Según Varela (2005), la tibia y el peroné están separados en la familia Callitrichidae, específicamente en el género Callithrix; sin embargo, los resultados de las placas radiográficas muestran que en el Callimico goeldii están ligeramente fusionados en el tercio distal de los huesos. La tibia no es recta como describió Varela (2005) acerca de todos los monos neotropicales, pues por el contrario, tiene una ligera curva hacia distal que hace parecer que la tibia y el peroné son un hueso único.

La pelvis en Callimico goeldii tiene su ancho máximo al nivel de las eminencias iliopúbicas, lo cual contradice a la mayoría de reportes sobre primates que indican que la pelvis posee un ancho craneal a nivel de las crestas iliacas y un ancho caudal a nivel de las tuberosidades isquiáticas muy similar a la humana. Según refieren Kardong (1999) y Wolpoff (1999) se necesita una pelvis ancha para completar la amplitud de las orientaciones musculares y los ángulos favorables sobre el fémur. La postura vertical de los monos sitúa al tórax y parte del cuerpo muy por encima del centro de gravedad, por eso el ancho de la pelvis provee una base para el soporte de las vísceras.

De lo mencionado anteriormente, se han requerido ciertos cambios estructurales para estabilizar el porte erguido de los primates. Según Kardong (1999), las caderas tienen que soportar el peso de la parte superior del cuerpo, el ilion es ancho para aumentar la base de soporte de la cadera y, por consecuencia, la distancia entre el sacro y la cabeza del fémur se acorta. Este es el principio por el cual los primates y los seres humanos tienen en común una pelvis ancha; sin embargo, el ancho máximo de la pelvis es distinto en Callimico goeldii y esto se puede deber a la locomoción distinta de este primate. 
Según Garber y Porter (2009), comparado con otras especies de tamarinos y monos titís, los Callimico goeldii se caracterizan por un patrón de locomoción dominado por saltos hacía, y desde sub estratos verticales del bosque. Aunque todos los callitrícidos usan una postura erguida durante el forrajeo, la mayoría de las especies no saltan de manera vertical durante su desplazamiento. Por ejemplo, las especies del género Saguinus viajan de manera vertical solo un máximo de $7.7 \%$ del tiempo total del trayecto emprendido. A diferencia de lo manifestado por Garber y Leigh (2001) sobre Callimico goeldii, quienes manifiestan que esta especie viaja dando saltos verticales en un $23 \%$ del tiempo total del trayecto y en posición erguida, en un poco más del $40 \%$ del tiempo total del viaje. Porter (2004) encontró que, en comparación con los tamarinos, una significativa mayor proporción de locomoción en los Callimico goeldii incluían saltos verticales ( $45 \%$ del viaje en Callimicos en comparación al 22\% del viaje en Saguinus y $3 \%$ en otras especies neotropicales). Asimismo, encontró que la distancia promedio saltada por los Callimico goeldii es de 1.8 metros (0.2-4.3 m); adicionalmente, los saltos más largos no ocurrieron en soportes de mayor diámetro que para saltos más cortos.

Por otro lado, Garber y Porter (2009) realizaron un estudio de la cinética de los saltos de callitrícidos mantenidos en cautiverio, indicando que cuando saltan una distancia de $1 \mathrm{~m}$, las especies de marmosetas comunes y pigmeas tienen una velocidad de despegue lento y experimentan una significativa pérdida de altura antes de aterrizar; sin embargo, el género Callimico genera una mayor velocidad de despegue y gana o mantiene altura cuando saltan a esta misma distancia. Finalmente, Kardong (1999), indica que los huesos son más ligeros y débiles en una situación de tensión, pero más fuertes cuando se cargan por compresión, de allí que el constante salto vertical de Callimico goeldii durante su locomoción hace que la pelvis este comprimida.
La longitud del esqueleto, cola incluida, se encuentra dentro de los rangos referenciales al igual que el número de vértebras en el esqueleto de Callimico goeldii (Ankel-Simons, 2007). No obstante, el número de vértebras torácicas es el que más varía entre especies (entre 11 y 13), siendo en el presente estudio de 12. Esta variación en el número de vértebras, según Kardong (1999), se puede deber a que la evolución a través de los años hizo que el cuerpo cambie de acuerdo a las necesidades del organismo; en este caso los primates neotropicales y en especial Callimico goeldii, posee un porte erguido y una locomoción en saltos verticales, dando como resultado, debido a la compresión, un tórax acortado.

Estudios referidos a la evolución de los Platyrrhini muestran como el comportamiento locomotor influyó en la morfología del talus en este parvorder (Püschel et al., 2017); observándose en el presente estudio que el esqueleto de Callimico goeldii tiene proporciones que difieren de otras especies de la misma familia. Las mediciones indicaron que brazos, piernas y pies se encuentran por debajo de las proporciones descritas por AnkelSimons (2007), concluyendo que los miembros de esta especie son más cortos. Esto se puede deber a la locomoción propia de la especie, por saltos verticales; conservando la relación entre región torácica y lumbar del esqueleto, 50:50 al igual que la mayoría de monos neotropicales descrito por AnkelSimons (2007).

\section{Conclusiones}

- Los valores de exposición radiográficos óptimos en esta especie fueron para la cabeza y el tórax-abdomen de $50 \mathrm{kV}, 20$ $\mathrm{mA}, 0.03 \mathrm{~s}$ y para las extremidades de $50 \mathrm{kV}, 20 \mathrm{~mA}, 0.02 \mathrm{~s}$.

- La forma y las medidas del cráneo, húmero, radio, cúbito y fémur guardan relación con la anatomía general de los primates; observándose que la tibia y el 
peroné se hallan ligeramente fusionados en el tercio distal y poseen una ligera curvatura hacia distal.

- La pelvis es ancha y robusta, su ancho máximo es a nivel de las eminencias iliopúbicas y posee un tórax acortado debido posiblemente a su patrón de locomoción dominado por saltos verticales.

- Los miembros anteriores y posteriores son ligeramente cortos con respecto a otras especies de primates neotropicales posiblemente debido a su patrón de locomoción es a base de saltos verticales.

\section{Literatura Citada}

1. Ankel-Simons F. 2007. An introduction: primate anatomy. $3^{\text {rd }}$ ed. Durham, North Carolina, USA: Academic Press. 752 p.

2. Cornejo F. 2008. Callimico goeldii. The IUCN Red List of Threatened Species 2008: e.T3564A9947398. [Internet]. Available in: http://dx.doi.org/ 10.2305 / I U C N. U K. 2008 . RLTS.T3564A9947398.en

3. Fernández J, Moreno I. 2004. Radiología elemental del tórax. Barcelona: Ed Caduceo Multimedia. $220 \mathrm{p}$.

4. Fleagle J. 1999. Primate adaptation and evolution. $2^{\text {nd }}$ ed. New York: Academic Press. 596 p.

5. Garber P, Porter L. 2009. Trunk-totrunk leaping in wild Callimico goeldii in northern Bolivia. Neotrop Primates 16: 9-14. doi: 10.1896/044.016.0102

6. Garber PA, Leigh SR. 2001. Patterns of positional behavior in mixed-species troops of Callimico goeldii, Saguinus labiatus, and Saguinus fuscicollis in northwestern Brazil. Am J Primatol 54: 17-31. doi: 10.1002/ajp.1009

7. Groves C. 2001. Primate taxonomy. Smithsonian Series in Comparative Evolutionary Biology. Washington DC, USA: Smithsonian Institution. $350 \mathrm{p}$.
8. Hershkovitz P. 1977. Living new world monkeys (Platyrrhini). Vol 1. USA: University of Chicago Press. $1132 \mathrm{p}$.

9. Hill W. 1957. Primates: comparative anatomy and taxonomy: a monograph: Volume 3. Pithecoidea: Platyrrhini (families Hapalidae and Callimiconidae). UK: Edinburgh University Press. 354 p.

10. Kiessling F, Pichler BJ, 2011. Small animal imaging. Basics and practical guide. Germany: Springer-Verlag Berlin Heidelberg. 597 p.

11. Kardong K. 1999. Vertebrados: anatomía comparada, función y evolución. $2^{\text {da }}$ ed. España: McGraw-Hill Interamericana. $896 \mathrm{p}$

12. Lannoo M. 2008. Malformed frogs. The collapse of aquatic ecosystems. Bekerley, California, USA: University of California Press. 288 p.

13. Napier JR, Napier PH. 1985. The natural history of the primates. Cambridge. MIT Press. 200 p.

14. Porter L. 2004. Forest use and activity patterns of Callimico goeldii in comparison to two sympatric tamarins, Saguinus fuscicollis and Saguinus labiatus. Am J Phys Anthropol 124: 139153. doi: 10.1002/ajpa.10343

15. Preuschoft S. 2000. Primate faces and facial expressions. Social Res 67:245-271.

16. Püschel TA, Gladman JT, Bobe R, Sellers WI. 2017. The evolution of the platyrrhine talus: a comparative analysis of the phenetic affinities of the Miocene platyrrhines with their modern relatives. J Hum Evol 111: 179-201. doi: 10.1016/ j.jhevol.2017.07.015

17. Richter CB, Lehner NDM, HenricksonRV (1984). Primates. In: Fox JG, Cohen BJ, Loew FM (eds). Laboratory animal medicine. Orlando, USA: Academic Press. p 297-383.

18. Rylands AB, Mittermeier RA, Rodriguez-Luna. E 1995. A species list for the new world primates (Platyrrhini): distribution by country, endemism, and conservation status according to the 
Mace-Land system. Neotrop Primates 3: 113-160.

19. Schneider H, Sampaio I. 2015. The systematics and evolution of New World primates - a review. Mol Phylogenet Evol 82: 348-357. doi: 10.1016/ j.ympev.2013.10.017

20. Turnquist JE, Hong N. 1995. Functional morphology. In: Bennett $\mathrm{T}$, Abee C, Henrickson RV (eds). Nonhuman primates in biomedical research, biology, and management. San
Diego, USA: Academic Press. p 49-76.

21. Varela N. 2005. Consideraciones anatómicas de importancia clínica en los primates neotropicales. Rev Asoc Vet Vida Silvestre 1: 15- 27.

22. Varela N. 2007. Bases para el manejo, atención médico veterinaria y rehabilitación de pequeños primates neotropicales. $2^{\text {da }}$ ed. Bogotá, Colombia: Asociación de Veterinarios de Vida Silvestre. 56 p.

23. Wolpoff MH. 1999. Paleoanthropology. $2^{\text {nd }}$ ed. Boston: McGraw-Hill. 878 p. 